\title{
PENGEMBANGAN E-LEARNING DENGAN KELASE PADA MATA PELAJARAN ILMU PENGETAHUAN ALAM DI SEKOLAH MENENGAH PERTAMA
}

\author{
Alexander Hamonangan Simamora', Anak Agung Gede Agung ${ }^{2}$, \\ Luh Putu Putrini Mahadewi ${ }^{3}$ \\ 1,2,3Program Studi Teknologi Pendidikan \\ Universitas Pendidikan Ganesha \\ Singaraja, Indonesia \\ e-mail: alexander.simamora@gmail.com¹,agung2056@undiksha.ac.id², \\ Ipp-mahadewi@undiksha.ac.id ${ }^{3}$
}

\begin{abstract}
Abstrak
Masalah yang ditemukan di SMP Negeri 2 Singaraja adalah hasil belajar IPA siswa belum memuaskan. Penelitian ini bertujuan untuk (1) mendeskripsikan rancang bangun pengembangan e-learning (2) mendeskripsikan kualitas hasil validasi pengembangan $e$ learning yang dikembangkan menurut review para ahli dan uji coba produk, (3) mengetahui efektivitas e-learning yang dikembangkan. Penelitian ini adalah penelitian pengembangan. Model pengembangan yang digunakan adalah model Hannafin and Peck. Data yang dikumpulkan dalam penelitian ini adalah data kuantitatif dan kualitatif. Metode pengumpulan data yang digunakan adalah metode pencatatan dokumen, kuesioner dan tes. Hasil penelitian adalah sebagai berikut. (1) Rancang bangun $e-$ learning mata pelajaran IPA dengan model Hannafin and Peck meliputi tiga tahapan. (2) E-learning mata pelajaran IPA yang dikembangkan valid dengan: (a) hasil review ahli isi mata pelajaran menunjukkan e-learning berpredikat sangat baik $(91,4 \%)$, (b) hasil review ahli e-learning menunjukkan produk berpredikat baik $(90,06 \%)$, (c) hasil review ahli desain pembelajaran menunjukkan e-learning berpredikat sangat baik $(89,02 \%)$, (d) hasil uji coba perorangan, uji coba kelompok kecil dan uji coba lapangan menunjukkan e-learning berpredikat sangat baik $(89,93 \%),(89,34 \%)$ dan $(83,03 \%)$. (3) Efektivitas pengembangan menunjukkan bahwa e-learning yang dikembangkan efektif meningkatkan hasil belajar IPA (thitung $=25,89>$ tabel $=2,390$, pada taraf signifikansi $5 \%$ ). Ini berarti bahwa e-learning terbukti efektif secara signifikan dapat meningkatkan hasil belajar IPA.
\end{abstract}

Kata-kata kunci : e-learning, Hannafin \& Peck, Pengembangan

\begin{abstract}
The learning outcomes of the IX grade students at SMP Negeri 2 Singaraja especially in biology subject were not yet satisfactory. Furthemore, this research aims to (1) describe the architecture development of e-learning in biology subjects, (2) describe the quality of the results of the validation of the development of e-learning are developed according to the review experts and product trials in biology subjects, (3) test the effectiveness of $e$ learning developed against the results of the study biology subjects. This research is the development. The development model used is the Hannafin and Peck model.The data collected in this research is quantitative and qualitative data. Data was collected using the method of recording documents, questionnaires and tests. The results of this research are as follows. (1) The design of e-learning biology subjects with the Hannafin and Peck model includes three phases. (2) E-learning biology subjects developed valid with: (a) the results of expert review the contents of the subjects showed predicated $e$ learning is very good $(92 \%)$, (b) the results of an e-learning expert reviews show products predicated good $(89,33 \%)$, (c) the results of expert review of instructional design e-learning predicated showed very good (93\%), (d) the results of individualtrials, small group trial and field trials demonstrate e-learning is predicated very good $(90,22 \%),(90.11 \%)$ and $(90 \%)$. (3) The effectiveness development shows that $e$ learning developed can effectively improve the learning results of science (tcount $=$
\end{abstract}


$25,89>\mathrm{t}$-table $=2,390$, significance level $5 \%$ ). That means e-learning proven to be effective can significantly improve Biology learning outcomes.

Keywords: Development, e-learning, Hannafin \& Peck

\section{Pendahuluan}

Belajar itu senantiasa merupakan perubahan tingkah laku atau penampilan, dengan serangkaian kegiatan misalnya dengan membaca, mengamati, mendengarkan, meniru dan lain sebagainya.Juga belajar itu akan lebih baik kalau subyek belajar itu mengalami atau melakukannya, jadi tidak bersifat verbalistik. Belajar sebagai kegiatan individu sebenarnya merupakan rangsangan-rangsangan individu yang dikirim kepadanya oleh lingkungan. Dengan demikian terjadinya kegiatan belajar yang dilakukan oleh seorang individu dapat dijelaskan dengan rumus antara individu dan lingkungan (Herawati, 2015). Mata pelajaran IPA merupakan salah satu mata pelajaran yang berupaya untuk membekali siswa dengan berbagai kemampuan tentang cara mengetahui dan memahami konsep ataupun fakta secara mendalam. Mengingat jumlah konsep dan keterampilan harus dikuasai siswa melalui pertemuan di kelas ini tidak didukung oleh waktu belajar yang kurang memadai, dimana waktu untuk satu kali tatap muka dirasa kurang memenuhi, maka diperlukan suatu sistem dan medium untuk pelaksanaan perkuliahan yang memungkinkan penguasaan pengetahuan dan keterampilan secara utuh bagi siswa. Menurut Mujakir (2015) Ilmu pengetahuan alam merupakan mata pelajaran yang mengkoordinasikan berbagai disiplin ilmu sublintas mata pelajaran seperti biologi, fisika, kimia, geologi, dan antariksa. Sebenarnya ilmu pengetahuan alam dapat juga dipadukan dengan mata pelajaran lain di luar bidang kajian ilmu pengetahuan alam, karena ilmu pengetahuan alam bukan sekedar gabungan dari biologi, fisika, kimia, dan antariksa tetapi juga merupakan integrasi kajian ilmu alamiah. Aspek pokok dalam pembelajaran IPA adalah anak dapat menyadari keterbatasan pengetahuannya, membangkitkan rasa ingin tahu untuk menggali berbagai pengetahuan baru dan akhirnya dapat mengaplikasikannya dalam kehidupan berdasarkan informasi yang disampaikan guru. Kedudukan guru mempunyai arti penting dalam pendidikan. Arti penting itu bertolak dari tugas dan tanggung jawab guru yang besar untuk mencerdaskan peserta didiknya. Guru dijadikan tumpuan harapan semua orang untuk mampu menjadikan peserta didik berhasil, apakah itu didalam bidang intelektual maupun perilakunya. Menurut Hutauruk (2018) IPA merupakan mata pelajaran yang sangat penting untuk dipelajari di tingkat SD, sebab membahas tentang peristiwaperistiwa yang terjadi di alam dan dekat dengan kehidupan peserta didik tersebut. Pendidikan IPA di sekolah dasar juga diharapkan dapat menjadi wahana peserta didik untuk mempelajari diri sendiri dan alam sekitar, serta prospek pengembangan lebih lanjut dalam menerapkannya di kehidupan sehari-hari. Proses pembelajaran IPA harus menekankan pada pemberian pengalaman secara langsung oleh peserta didik untuk mengembangkan kompetensi agar menjelajahi dan memahami alam sekitar, yang pada akhirnya mereka menemukan sendiri konsep materi pelajaran yang sedang dipelajarinya. Menurut Sulthon (2016) Pembelajaran IPA tidak bisa dengan cara menghafal atau pasif mendengarkan guru menjelaskan konsep namun siswa sendiri yang harus melakukan pembelajaran melalui percobaan, pengamatan maupun bereksperimen secara aktif yang akhirnya akan terbentuk kreativitas dan kesadaran untuk menjaga dan memperbaiki gejala-gejala alam yang terjadi untuk selanjutnya membentuk sikap ilmiah yang pada gilirannya akan aktif untuk menjaga kestabilan alam ini secara baik dan lestari. Menurut Suriyani (2017) Pembelajaran IPA di sekolah diharapkan agar siswa mempunyai keterampilan berpikir kritis dan memecahkan masalah. Sebab, keterampilan berpikir kritis bukanlah pembawaan manusia sejak lahir namun bisa ditumbuh kembangkan. Dalam hal ini, guru memegang peranan penting dalam usaha pengembangan keterampilan berpikir kritis khususnya pada mata pelajaran sistem pencernaan manusia, agar siswa dapat memiliki pengalaman bagaimana menemukan satu konsep. 
Berdasarkan hasil observasi dan wawancara yang dilakukan dengan guru pengajar IPA kelas IX di SMP Negeri 2 Singaraja, diperoleh informasi mengenai proses pembelajaran yang selama ini berlangsung. Guru lebih sering menggunakan metode ceramah daripada menggunakan media pembelajaran, sehingga siswa cenderung acuh dan tidak memperhatikan materi yang disampaikan oleh guru. Ditambah lagi penggunaan media pembelajaran terlalu monoton menjadikan siswa semakin malas untuk belajar. Kemudian keterbatasan jam pelajaran, pada mata pelajaran IPA siswa bertatap muka dengan guru hanya dua kali seminggu dengan alokasi waktu 2 × 45 menit, sehingga materi yang disampaikan kurang optimal.

Dengan kemajuan teknologi diharapkan guru dapat mengembangkan pembelajaran dengan memanfaatkan teknologi informasi dan komunikasi sehingga pembelajaran menjadi lebih bermakna untuk siswa baik itu pembelajaran di sekolah maupun diluar sekolah secara mandiri. Salah satu perkembangan inovasi bidang teknologi adalah penggunaan e-learning. Dengan e-learning diharapkan dapat membantu siswa dalam proses belajarnya, sehingga siswa dapat berkomunikasi secara langsung maupun tidak langsung, baik itu dalam pembelajaran di kelas maupun di luar kelas.

Berdasarkan paparan tersebut, maka dalam penelitian ini dicoba untuk mengembangkan e-learning dengan Kelase pada mata pelajaran IPA kelas IX semester genap tahun pelajaran 2018/2019 di SMP Negeri 2 Singaraja.

Sejalan dengan pemaparan di atas rumusan masalah pada penelitian ini adalah sebagai berikut: (1) Bagaimanakah rancang bangun pengembangan e-learning pada mata pelajaran IPA kelas IX semester genap tahun pelajaran 2018/2019 di SMP Negeri 2 Singaraja?; (2) Bagaimanakah kualitas hasil validasi e-learning yang dikembangkan menurut review para ahli dan uji coba produk pada mata pelajaran IPA kelas IX semester genap tahun pelajaran 2018/2019 di SMP Negeri 2 Singaraja?; (3) Bagaimanakah efektivitas e-learning yang dikembangkan terhadap hasil belajar mata pelajaran IPA pada siswa kelas IX semester genap tahun pelajaran 2018/2019 di SMP Negeri 2 Singaraja?.

Berdasarkan rumusan masalah, adapun tujuan yang ingin dicapai dalam penelitian ini yaitu: (1) Untuk mendeskripsikan rancang bangun pengembangan e-learning pada mata pelajaran IPA kelas IX semester genap tahun pelajaran 2018/2019 di SMP Negeri 2 Singaraja. (2) Untuk mendeskripsikan kualitas hasil validasi e-learning yang dikembangkan menurut review para ahli dan uji coba produk pada mata pelajaran IPA kelas IX semester genap tahun pelajaran 2018/2019 di SMP Negeri 2 Singaraja. (3) Untuk menguji efektivitas e-learning yang dikembangkan terhadap hasil belajar mata pelajaran IPA pada siswa kelas IX semester genap tahun pelajaran 2018/2019 di SMP Negeri 2 Singaraja.

\section{Metode}

Dalam penelitian ini peneliti menggunakan model pengembangan Hannafin dan Peck (analisis kebutuhan, desain/ perancangan, pengembangan dan implementasi). Penelitian ini menggunakan tiga metode pengumpulan data untuk menjawab permasalahan mengenai rancang bangun pengembangan e-learning, kualitas hasil validasi e-learning serta efektivitas $e$ learning yaitu metode pencatatan dokumen, kuesioner/angket dan tes. Dalam penelitian pengembangan ini digunakan tiga teknik analisis data, yaitu teknik analisis deksriptif kualitatif, teknik analisis deskriptif kuantitatif, dan teknik analisis statistik inferensial (uji-t)

$$
\text { Persentase }=\frac{\Sigma(\text { Jawaban } \times \text { bobottiap pilihan) }}{n \times b o b o t t e r t i n g g i} \times 100 \%
$$

(Tegeh dan Kirna, 2010:101)

Keterangan:

$\Sigma=$ Jumlah

$\mathrm{n}=$ Jumlah seluruh item angket 
Sebelum melakukan uji hipotesis (uji-t berkorelasi) dilakukan uji prasyarat (uji normalitas dan homogenitas). Rumus untuk menghitung uji prasyarat dan uji hipotesis (uji-t berkorelasi) adalah sebagai berikut. Uji normalitas dilakukan untuk mengetahui apakah sebaran skor pada setiap variabel berdistribusi normal atau tidak, untuk itu dapat digunakan rumus Liliefors. Adapun rumusnya sebagai berikut.

Menurut Koyan (2012: 109) adapun cara yang dapat dilakukan untuk menguji normalitas suatu data dengan teknik liliefors. Jika $L_{0}<L_{t}$, maka $H_{0}$ diterima, sehingga dapat disimpulkan bahwa sampel berasal dari populasi yang berdistribusi normal.

Uji homogenitas ini dilakukan untuk mencari tingkat kehomogenan secara dua pihak yang diambil dari kelompok-kelompok data terpisah dari satu sampel. Untuk menguji homogenitas varians data sampel digunakan uji Fisher $(F)$ dengan rumus sebagai berikut.

$$
F_{\text {hit }}=\frac{\text { Varians terbesar }}{\text { Varians terkecil }}
$$

(Koyan, 2012:40)

Teknik analisis yang digunakan untuk pengujian hipotesis adalah teknik analisis uji-t. Rumus untuk uji-t berkorelasi adalah sebagai berikut.

$$
t=\frac{\overline{X_{1}}-\overline{X_{2}}}{\sqrt{\frac{s_{1}{ }^{2}}{n_{1}}+\frac{s_{2}{ }^{2}}{n_{2}}-2 r\left(\frac{s_{1}}{\sqrt{n_{1}}}\right)\left(\frac{s_{2}}{\sqrt{n_{2}}}\right)}}
$$

(Sumber: Koyan, 2012:34)

\section{Hasil dan Pembahasan}

Hasil penelitian dibahas lima hal pokok, yaitu (1) Rancang bangun e-learning, (2) Kualitas hasil validasi pengembangan e-learning, (3) Revisi pengembangan produk, (4) Uji prasyarat analisis data dan (5) Uji hipotesis.

Analisis kebutuhan dilakukan sebagai tahapan awal dalam mengembangkan e-learning. Tahap analisis kebutuhan ini dilakukan melalui wawancara dengan guru mata pelajaran IPA di SMP Negeri 2 Singaraja, Ibu Luh Ratna Tirtawati, S.Pd., M.Pd. Berdasarkan hasil wawancara diketahui bahwa permasalahan yang dihadapi selama proses pembelajaran yakni keterbatasan jam pelajaran pada mata pelajaran IPA sehingga menjadikan kurang optimalnya penyampaian materi pelajaran yang bisa dilakukan oleh pendidik.

Perancangan desain e-learning dilakukan dengan memilih dan menetapkan perangkat lunak/software yang digunakan untuk mengembangkan e-learning. Dalam pengembangan / mengimplementasikan e-learning, pengembang dituntut untuk mengaplikasikan keterampilan yang dimiliki sehingga e-learning dapat dikembangkan sesuai dengan desain yang telah dirancang. Tahap berikutnya yakni tahap penggunaan produk oleh pengguna. Mahadewi, (2013) menyatakan setelah dilakukan testing terhadap keseluruhan sistem, maka tahap berikutnya adalah tahap penggunaan produk di lingkungan pengguna itu sendiri atau dikenal dengan istilah pelepasan produk.

Uji Ahli Isi Mata Pelajaran. Produk e-learning dinilai oleh seorang ahli isi sekaligus sebagai guru mata pelajaran IPA di SMP Negeri 2 Singaraja atas nama Luh Ratna Tirtawati, S.Pd., M.Pd. Berdasarkan hasil penilaian dari ahli isi mata pelajaran, setelah dikonversikan dengan tabel konversi, persentase tingkat pencapaiannya sebesar $91,4 \%$ berada pada kualifikasi sangat baik. 
Uji Ahli Desain Pembelajaran. Produk e-learning ini diujikan kepada seorang ahli desain pembelajaran atas nama Dr. I Made Tegeh, M.Pd. Berdasarkan hasil penilai dari ahli desain pembelajaran, setelah dikonversikan dengan tabel konversi persentase tingkat pencapaiannya sebesar $89,02 \%$ berada pada kualifikasi sangat baik.

Uji Ahli E-learning. E-learning diujikan kepada seorang ahli e-learning atas nama Adrianus I Wayan llia Yuda Sukmana, S.Kom., M.Pd. Berdasarkan hasil penilaian dari ahli elearning, setelah dikonversikan dengan tabel konversi, persentase tingkat pencapaiannya sebesar $90,06 \%$.

Uji Coba Perorangan. Sebagai subjek dari uji coba perorangan ini adalah siswa kelas IX MIA 2 SMP Negeri 2 Singaraja berjumlah 3 (tiga) orang dengan hasil penilaian rerata persentase $=269,8: 3=89,93 \%$. Rerata persentase $89,93 \%$ ini berada pada kualifikasi sangat baik. Uji Coba Kelompok Kecil berjumlah 12 (dua belas) orang dengan hasil penilaian rerata persentase $=1072,1: 12=89,34 \%$. Rerata persentase $89,34 \%$ ini berada pada kualifikasi sangat baik. Uji Coba Lapangan berjumlah 40 (empat puluh) orang dengan hasil penilaian rerata persentase $=3350.0: 40=83,75 \%$. Rerata persentase $83,75 \%$ ini berada pada kualifikasi baik.

Revisi pengembangan produk. Dalam pengembangan produk e-learning ini melalui enam tahapan yaitu (1) ahli isi mata pelajaran, (2) ahli e-learning, (3) ahli desain pembelajaran, (4) uji coba perorangan, (5) uji coba kelompok kecil, (6) uji coba lapangan. Dalam ke enam tahapan revisi tersebut, ada sedikit revisi dan ada beberapa masukan serta saran dari para ahli dan subjek uji coba.

Berdasarkan nilai pretest dan posttest 40 orang siswa tersebut, maka dilakukan uji-t untuk sampel berkorelasi. Rata-rata nilai pretest adalah 57,87 dan rata-rata nilai posttest adalah 89,5 . Peningkatan rata-rata nilai siswa ini juga dapat dilihat berdasarkan jawabanjawaban siswa saat menjawab tes. Sebagian besar jawaban siswa yang salah saat pretest dalam menempuh posttest jawaban tersebut menjadi benar. Dilihat dari konversi hasil belajar siswa kelas IX di SMP Negeri 2 Singaraja, nilai rata-rata posttest siswa yaitu 89,5 berada pada kualifikasi sangat baik. Ini berarti media e-learning efektif dalam membantu siswa dalam meningkatkan hasil belajar siswa pada mata pelajaran IPA tahun pelajaran 2018/2019. Ini dikarenakan e-learning sudah mencakup keseluruhan materi pembelajaran sehingga e-learning dapat menumbuhkan motivasi belajar siswa mengoptimalkan pemahaman siswa terhadap materi pembelajaran.

\section{Simpulan dan Saran}

Berdasarkan rumusan masalah, hasil analisis data dan pembahasan pada penelitian ini, maka dapat diambil simpulan sebagai berikut: Pertama, rancang bangun e-learning dikembangkan pada semua tahapan dari model pengembangan Hannafin dan Peck. Kedua, kelayakan hasil pengembangan e-learning pada (1) ahli desain pembelajaran berpredikat sangat baik (89,02\%), (2) ahli isi mata pelajaran berpredikat sangat baik $(91,4 \%)$, (3) ahli elearning berpredikat baik $(90,06 \%)$, (4) uji coba perorangan berpredikat sangat baik $(89,93 \%)$, (5) uji coba kelompok kecil berpredikat sangat baik $(89,34 \%)$, dan (6) uji coba lapangan berpredikat sangat baik (83,75\%). Ketiga, e-learning terbukti efektif secara signifikan dapat meningkatkan hasil belajar IPA kelas IX semester genap tahun pelajaran 2018/2019 di SMP Negeri 2 Singaraja. Efektivitas produk pengembangan e-learning pada pembelajaran di ukur dengan menggunakan skor pretest dan posttest terhadap 40 orang siswa kelas IX MIA 3 di SMP Negeri 2 Singaraja. Rata-rata nilai pretest adalah 57,87 dan rata-rata nilai posttest adalah 89,5 . Setelah dilakukan penghitungan secara manual diperoleh hasil t hitung sebesar 25,890 . Kemudian harga t hitung dibandingkan dengan harga pada t tabel dengan $\mathrm{db}=\mathrm{n} 1+\mathrm{n} 2-2=$ $40+40-2=78$. Harga t tabel untuk db 78 dan dengan taraf signifikansi $5 \%(\alpha=0,05)$ adalah 2,390. Dengan demikian, harga t hitung lebih besar daripada harga t tabel sehingga $\mathrm{H} 0$ ditolak dan $\mathrm{H} 1$ diterima. Ini berarti, media e-learning IPA efektif dalam meningkatkan hasil belajar siswa pada mata pelajaran IPA di SMP Negeri 2 Singaraja tahun pelajaran 2018/2019 
Saran-saran yang disampaikan berkenaan dengan pengembangan e-learning ini dikelompokkan menjadi empat, yaitu: Kepada Siswa, disarankan agar dapat memanfaatkan elearning secara optimal. E-learning tidak hanya dapat dimanfaatkan di sekolah saja, namun dapat dimanfaatkan dimana saja dan kapan saja pada saat siswa ingin belajar. Dengan pemanfaatan e-learning secara maksimal, maka diharapkan hasil belajar siswa akan meningkat lebih optimal. Kepada Guru, disarankan agar menggunakan e-learning pada mata pelajaran IPA, mengingat dengan menggunakan e-learning minat dan perhatian siswa dalam belajar lebih meningkat. Disarankan juga kepada guru agar dapat mengembangkan e-learning sejenis secara sendiri, sebab dengan dikembangkannya e-learning sesuai dengan pembelajaran yang guru inginkan, maka akan dapat mengatasi permasalahan keterbatasan media, ruang dan waktu dalam pengelolaan proses pembelajaran. Kepada Kepala Sekolah, disarankan agar mengambil kebijakan untuk mengadakan suatu pelatihan bagi guru-guru binaannya dalam mengembangkan maupun penggunaan e-learning di SMP Negeri 2 Singaraja. Kepala sekolah juga disarankan dapat melakukan pengadaan fasilitas pendukung penggunaan e-learning di sekolah dengan mengajukan permohonan kepada pihak yang terkait. Kepada Peneliti Lain, disarankan agar hasil penelitian ini dapat dijadikan referensi melakukan penelitian sejenis yang bersifat pengembangan lebih lanjut dan lebih luas.

\section{Daftar Pustaka}

Agung, A.A. Gede. 2014. Metodologi Penelitian Pendidikan. Buku Ajar Metodologi Penelitian Pendidikan. Singaraja: Undiksha

Duniawan, I. G. 2014. "Integrasi TIK, E-Learning Solusi Alternatif dalam Kegiatan Pembelajaran". Makalah disajikan dalam Seminar Problematika Teknologi Pendidikan. Jurusan Teknologi Pendidikan. Singaraja, 22 Desember 2014.

Fithri, D. L. 2014. "Analisa dan Perancangan E-Learning Pembelajaran Grammer untuk Meningkatkan Potensi Siswa". Jurnal SIMETRIS, Vol 5 No 1 April 2014 ISSN: 22524983.

Herawati. 2015. Penerapan Model Pembelajaran Two Stay Two Stray untuk Meningkatkan Prestasi Belajar Siswa Pada Materi Keliling dan Luas Lingkaran di Kelas VI SD Negeri 53 Banda Aceh. Jurnal Peluang, Volume 3, Nomor 2, Hal. 95-105. Tersedia Pada: http://jurnal.unsyiah.ac.id/peluang/article/download/5720/4731.

Hutauruk, Pindo, Rinci Simbolon. 2018. Meningkatkan Hasil Belajar Siswa dengan Alat Peraga pada Mata Pelajaran IPA Kelas IV SDN Nomor 14 Simbolon Purba. SEJ (School Education Journal) Vol. 8. No 2 Hal. 121-129. Tersedia Pada: https://jurnal.unimed.ac.id/2012/index.php/school/article/download/9770/9295.

Koyan, I Wayan. 2012. Statistik Pendidikan. Singaraja: Undiksha.

Mahadewi, Luh Putu Putrini. 2013. Pemrograman Dengan Teks. Singaraja: Undiksha

Mahadewi, Luh Putu Putrini. 2016. Blended Learning Dinamisasi Seting Pembelajaran. Singaraja: FIP Undiksha.

Mahadewi, Luh Putu Putrini dan I Kadek Edi Yudiana. 2016. Pengembangan Prototype Pembelajaran Online Dengan Cognitive Load Theory Pada Mata Kuliah Strategi Pembelajaran di Fakultas IImu Pendidikan. (Laporan Penelitian). Singaraja: FIP Undiksha. 
Mujakir. 2015.Kreativitas Guru dalam Pembelajaran IPA di Sekolah Dasar. Lantanida Journal, Vol. 3 No. 1, Hal. 82-92. Tersedia Pada: https://www.jurnal.arraniry.ac.id/index.php/lantanida/article/download/1443/pdf.

Rusman. 2012. Model-model Pembelajaran. Depok: PT Rajagrafindo Persada.

Sulthon. 2016. Pembelajaran IPA yang Efektif dan Menyenangkan Bagi Siswa Madrasah Ibtidaiyah (MI). Elementary Vol. $4 \int$ No. 1 Hal. 38-54. Tersedia Pada: http://journal.stainkudus.ac.id/index.php/elementary/article/download/1969/pdf.

Suriyani, Henny Irma, Murni Sabilu, Safilu. 2017. Pengaruh Pembelajaran Terpadu Tipe Connected Menggunakan Pendekatan Scientific Terhadap Keterampilan Berpikir Kritis Siswa Pada Materi Sistem Pencernaan Manusia Di Kelas VIII SMP Negeri 10 Kendari. J. A $M$ M $\quad$ I $\quad$ B $\quad$ I 2 (1) hal. $(75$ - 83). Tersedia Pada: http://ojs.uho.ac.id/index.php/ampibi/article/download/5060/3781.

Tegeh, I Made dan I Made Kirna. 2010. Metode Penelitian Pengembangan 